Supporting Information for

\title{
Ruthenium Nanoframes in the Face-Centered Cubic Phase: Facile Synthesis and Their Enhanced Catalytic Performance
}

Ming Zhao,${ }^{\dagger}$ Zachary D. Hood, ${ }^{\dagger}, \#$ Madeline Vara,${ }^{\dagger}$ Kyle D. Gilroy, ${ }^{\dagger}$ Miaofang Chi, ${ }^{\#}$ and Younan Xia ${ }^{*}, \dagger, \downarrow$

†School of Chemistry and Biochemistry, Georgia Institute of Technology, Atlanta, Georgia 30332,

United States

The Wallace H. Coulter Department of Biomedical Engineering, Georgia Institute of Technology and Emory University, Atlanta, Georgia 30332, United States

${ }^{\#}$ Center for Nanophase Materials Sciences, Oak Ridge National Laboratory, Oak Ridge, Tennessee 37831, United States

*Corresponding author: younan.xia@bme.gatech.edu 


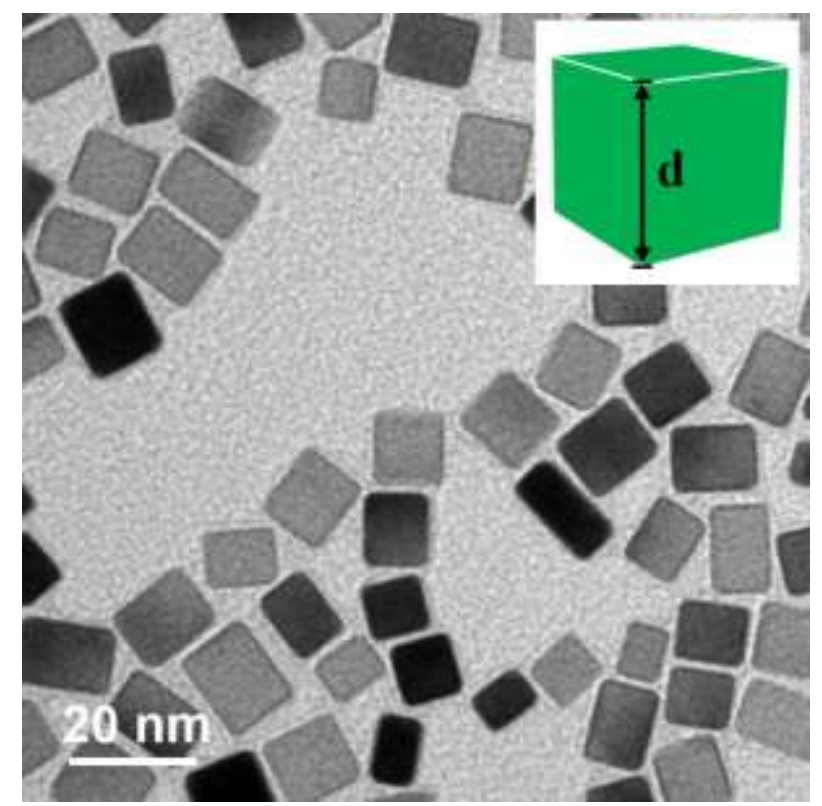

Figure S1. TEM image of the Pd nanocubes that served as seeds for the synthesis of Ru cuboctahedral nanoframes, showing an average size $(d)$ of $10 \mathrm{~nm}$. The inset shows a schematic of the Pd nanocube, together with the definition of size. 


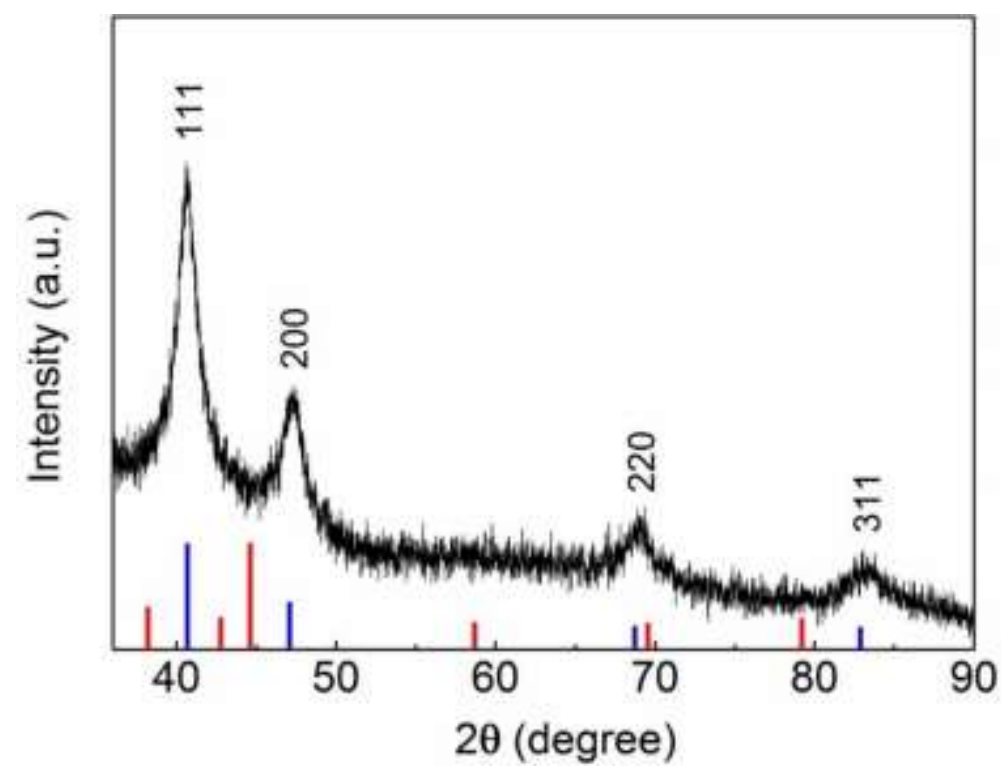

Figure S2. XRD pattern of the Ru cuboctahedral nanoframes prepared using the standard protocol, suggesting an $f c c$ phase. Blue bars: JCPDS no. 88-2333 ( $f c c$ Ru). Red bars: JCPDS no. 06-0663 (hcp Ru). 


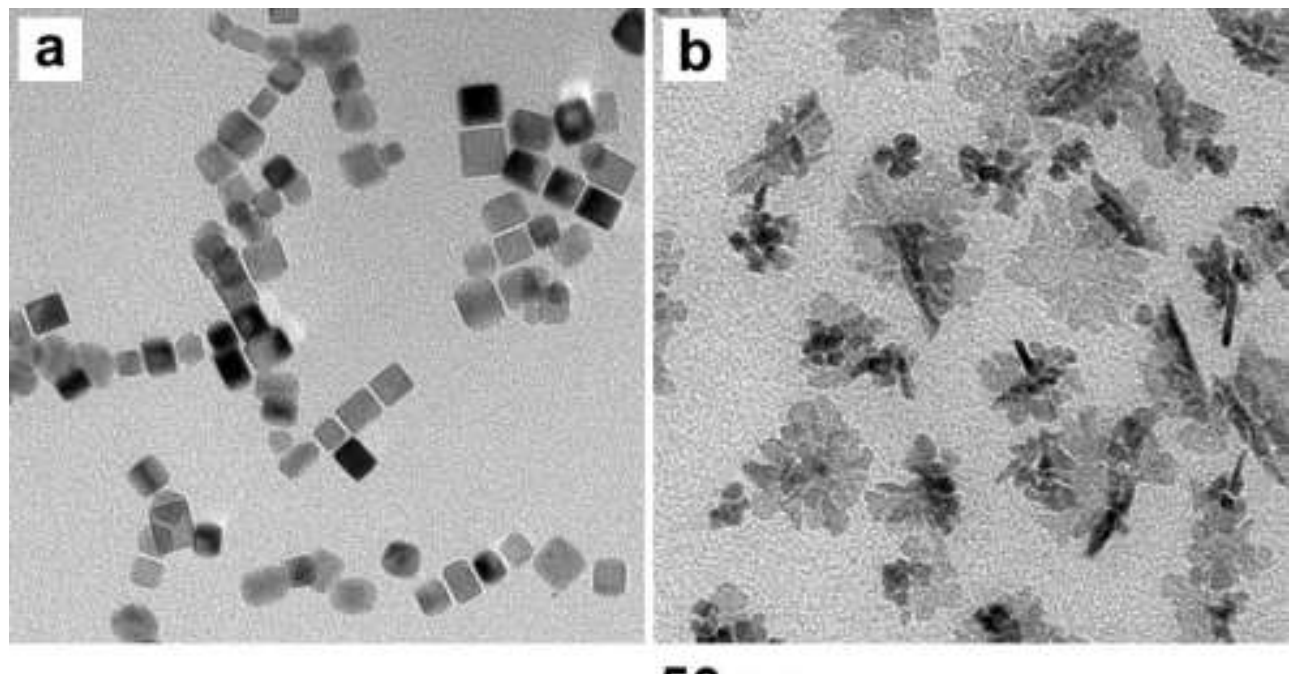

$50 \mathrm{~nm}$

Figure S3. TEM images of the solid products obtained using the standard protocol except for the absence of (a) Ru(III) precursor and (b) Pd cubic seeds, respectively. 

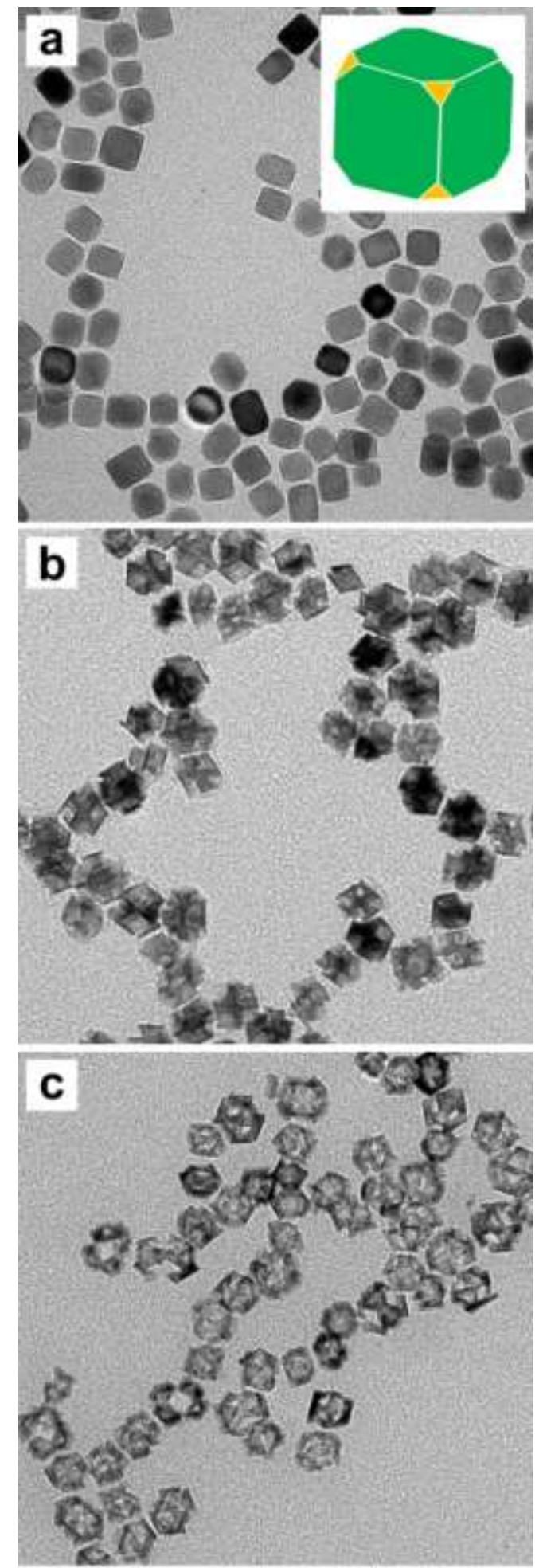

\section{$25 \mathrm{~nm}$}

Figure S4. TEM images of (a) the truncated Pd nanocubes prepared from 10-nm Pd nanocubes, and the corresponding (b) $\mathrm{Pd}-\mathrm{Ru}$ nanocrystals and (c) $\mathrm{Ru}$ nanoframes prepared using these seeds. The inset in (a) shows a schematic of the truncated Pd nanocube, in which the $\{100\}$ and $\{111\}$ facets are indicated by green and yellow colors, respectively. 


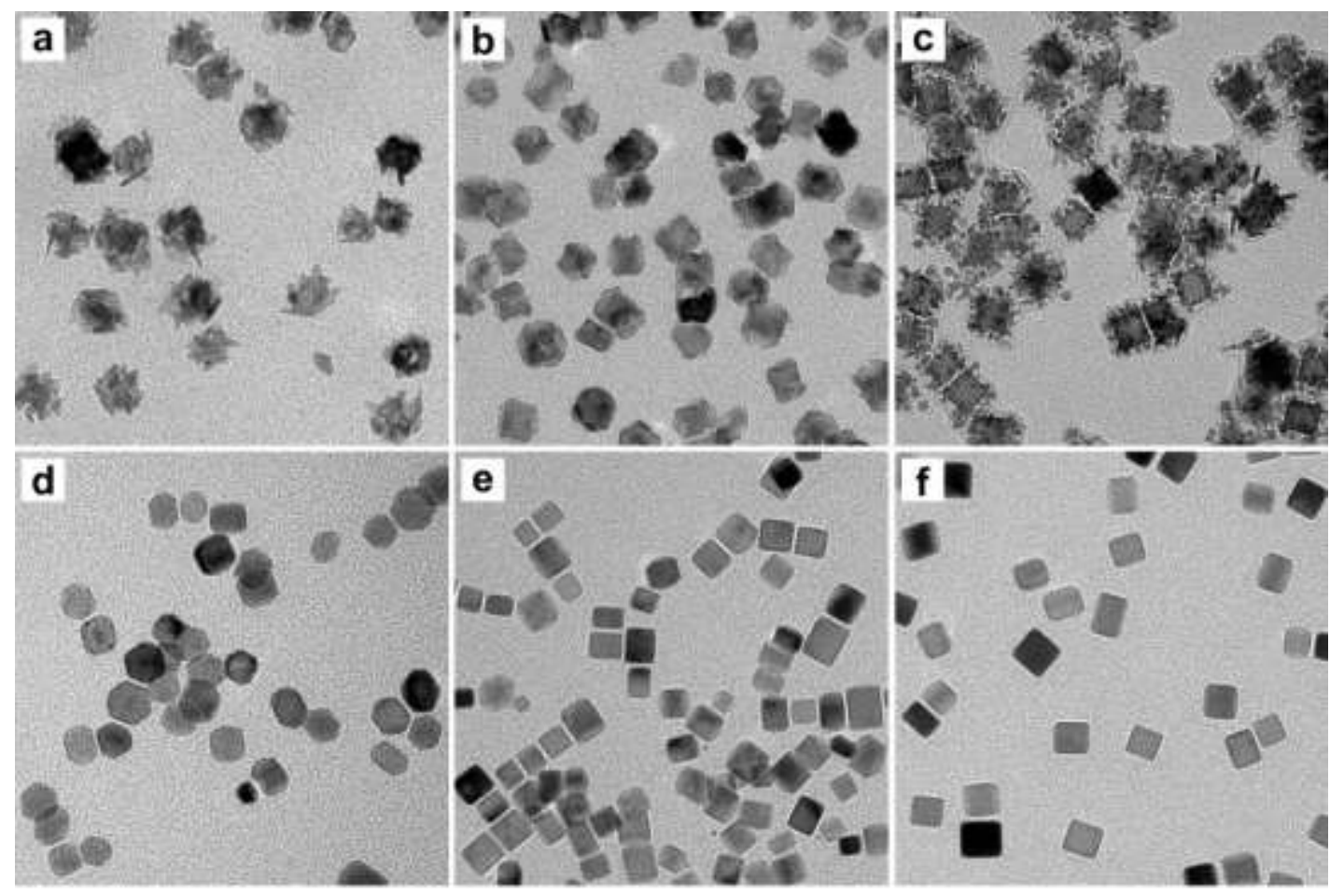

$25 \mathrm{~nm}$

Figure S5. TEM images of the Pd-Ru nanocrystals prepared using the standard protocol except for the involvement of different amounts of $\mathrm{KBr}$ and $\mathrm{Ru}(\mathrm{III})$ precursor: (a) $50 \mathrm{mg}$ of $\mathrm{KBr}(\mathrm{Br}: \mathrm{Pd}$ $=45: 1 \mathrm{~mol} / \mathrm{mol}$ ) and $2.4 \mathrm{mg}$ of $\mathrm{Ru}(\mathrm{III})$ precursor $(\mathrm{Ru}: \mathrm{Pd}=2: 3 \mathrm{~mol} / \mathrm{mol})$, (b) $5 \mathrm{mg}$ of $\mathrm{KBr}$ $(\mathrm{Br}: \mathrm{Pd}=4.5: 1 \mathrm{~mol} / \mathrm{mol})$ and $2.4 \mathrm{mg}$ of $\mathrm{Ru}(\mathrm{III})$ precursor $(\mathrm{Ru}: \mathrm{Pd}=2: 3 \mathrm{~mol} / \mathrm{mol})$, (c) no $\mathrm{KBr}$ and $2.4 \mathrm{mg}$ of $\mathrm{Ru}(\mathrm{III})$ precursor $(\mathrm{Ru}: \mathrm{Pd}=2: 3 \mathrm{~mol} / \mathrm{mol})$, (d) $50 \mathrm{mg}$ of $\mathrm{KBr}(\mathrm{Br}: \mathrm{Pd}=45: 1$ $\mathrm{mol} / \mathrm{mol})$ and no $\mathrm{Ru}(\mathrm{III})$ precursor, (e) $5 \mathrm{mg}$ of $\mathrm{KBr}(\mathrm{Br}: \mathrm{Pd}=45: 1 \mathrm{~mol} / \mathrm{mol})$ and no $\mathrm{Ru}(\mathrm{III})$ precursor, and (f) no $\mathrm{KBr}$ and no $\mathrm{Ru}(\mathrm{III})$ precursor. 


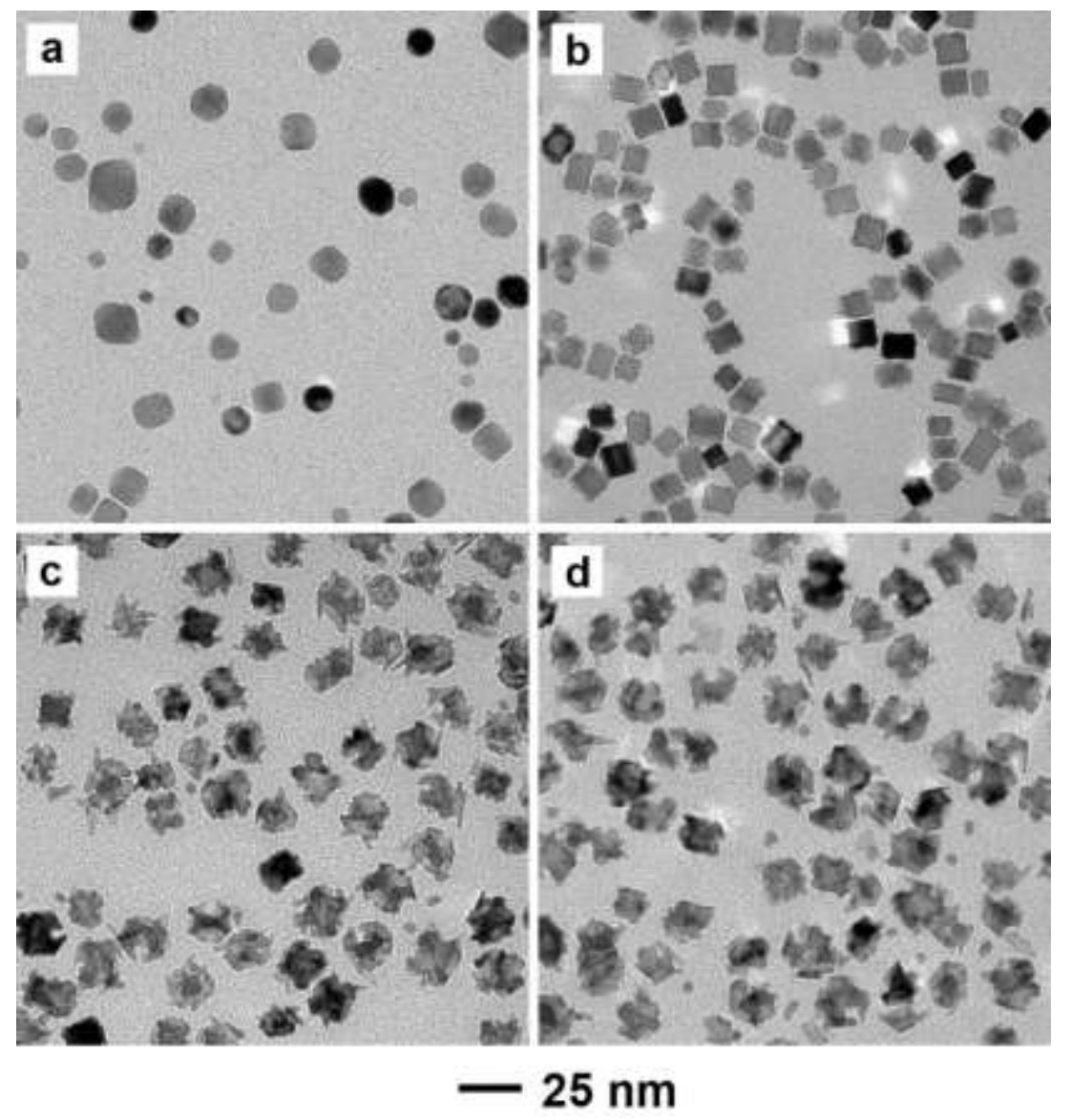

Figure S6. TEM images of the Pd-Ru nanocrystals prepared using the standard protocol except for the use of different reaction temperatures: (a) 140, (b) 160, (c) 200, and (d) $220^{\circ} \mathrm{C}$. 

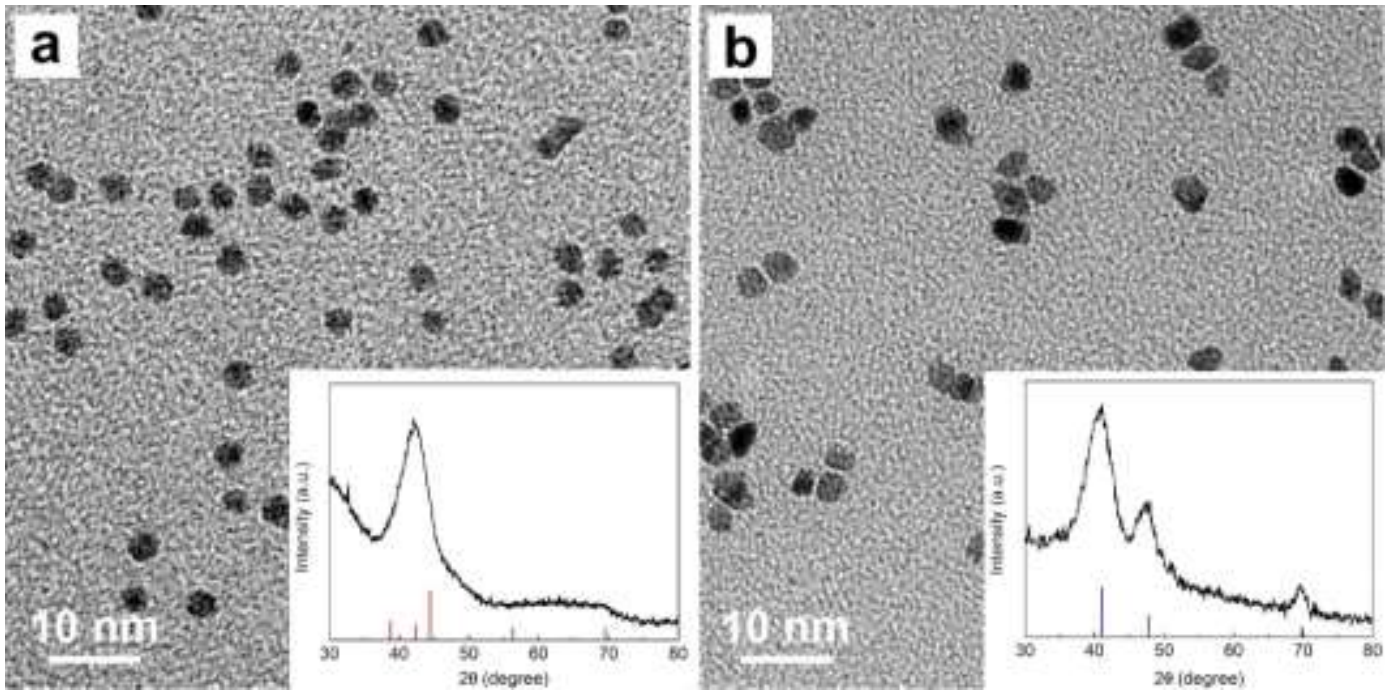

Figure S7. TEM images of the Ru nanoparticles with (a) $h c p$ and (b) $f c c$ phases, respectively. The insets show the corresponding XRD patterns. The characteristic peaks of $h c p$ and $f c c \mathrm{Ru}$ are marked by red and blue lines, respectively. Red bars: JCPDS no. 06-0663 (hcp Ru). Blue bars: JCPDS no. 88-2333 ( $f c c \mathrm{Ru})$. 

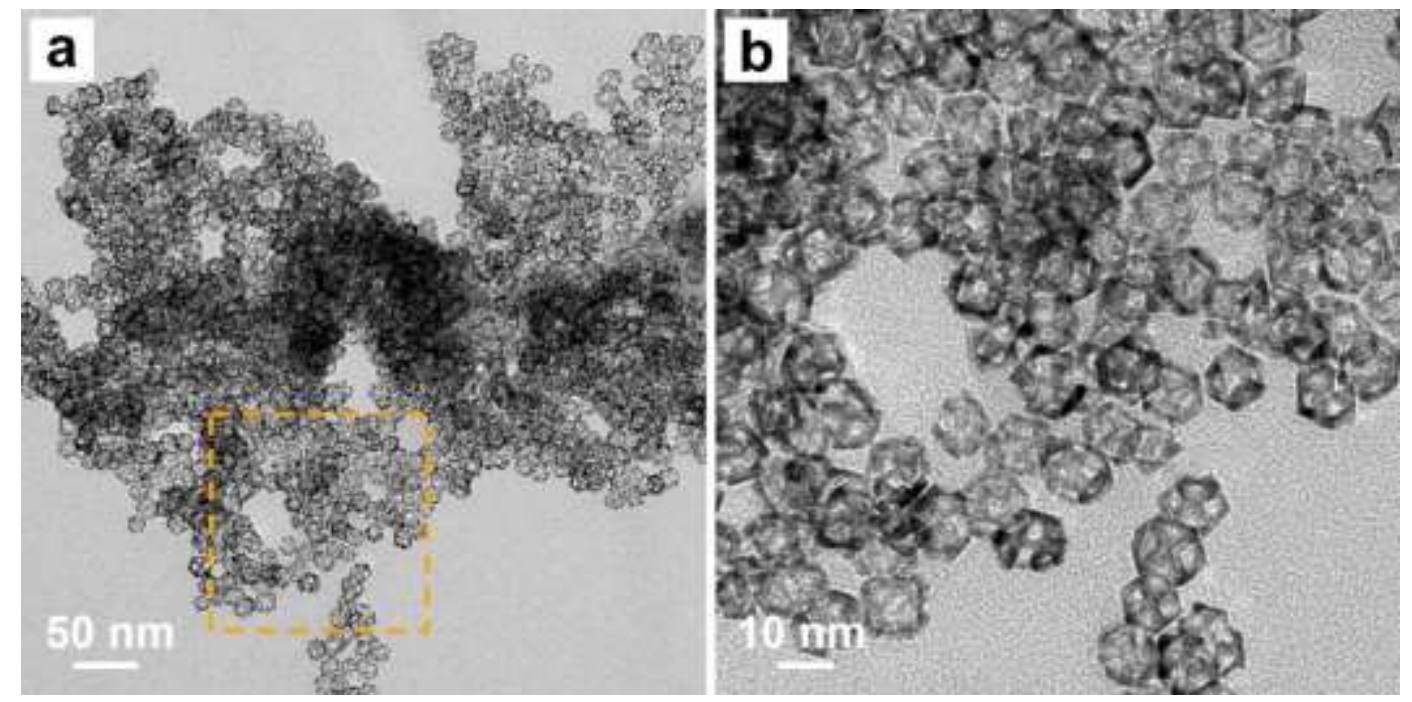

Figure S8. (a) TEM image of the Ru nanoframes after they had been used as catalysts for ten rounds of catalytic measurement towards hydrazine decomposition. (b) TEM image of the nanoframes at a higher magnification, taken from the region marked by a box in panel (a). 
Table S1. Elemental compositions of the intermediate products obtained at different stages of a standard synthesis.

\begin{tabular}{c|c|c}
\hline Reaction Time & Percentage of Pd (wt.\%) & Percentage of Ru (wt.\%) \\
\hline $10 \mathrm{~min}$ & 100.0 & 0.0 \\
\hline $1 \mathrm{~h}$ & 94.2 & 5.8 \\
\hline $2 \mathrm{~h}$ & 88.7 & 11.3 \\
\hline $4 \mathrm{~h}$ & 72.1 & 27.9 \\
\hline
\end{tabular}


Table S2. Elemental compositions of the Pd@Ru core-frame cuboctahedra and Ru cuboctahedral nanoframes prepared using the standard protocol.

\begin{tabular}{c|c|c}
\hline & Percentage of Pd (wt.\%) & Percentage of Ru (wt.\%) \\
\hline Before etching & 69.1 & 30.9 \\
\hline After etching & 6.6 & 93.4 \\
\hline
\end{tabular}


Table S3. Elemental compositions of the Pd@Ru core-frame cuboctahedra and resultant Ru nanoframes prepared using the standard protocol except for the use of truncated Pd cubes as seeds.

\begin{tabular}{c|c|c}
\hline & Percentage of Pd (wt.\%) & Percentage of Ru (wt.\%) \\
\hline Before etching & 70.1 & 29.9 \\
\hline After etching & 6.9 & 93.1 \\
\hline
\end{tabular}


Table S4. Elemental compositions of the $\mathrm{Pd}-\mathrm{Ru}$ nanocrystals prepared using the standard protocol except for the use of different reaction temperatures.

\begin{tabular}{c|c|c}
\hline Temperature $\left({ }^{\circ} \mathrm{C}\right)$ & Percentage of Pd (wt.\%) & Percentage of Ru (wt.\%) \\
\hline 140 & 99.4 & 0.6 \\
\hline 160 & 89.2 & 10.8 \\
\hline 200 & 66.9 & 33.1 \\
\hline 220 & 63.8 & 36.2 \\
\hline
\end{tabular}


Table S5. Summary of the $n\left(\mathrm{H}_{2}+\mathrm{N}_{2}\right) / \mathrm{n}\left(\mathrm{N}_{2} \mathrm{H}_{4}\right)$ ratio and $\mathrm{H}_{2}$ selectivity derived from different $\mathrm{Ru}$ catalysts after they had been subjected to ten rounds of measurements towards hydrazine decomposition.

\begin{tabular}{c|c|c|c|c|c|c}
\hline \multirow{2}{*}{ Round } & \multicolumn{3}{|c|}{$\mathrm{n}\left(\mathrm{H}_{2}+\mathrm{N}_{2}\right) / \mathrm{n}\left(\mathrm{N}_{2} \mathrm{H}_{4}\right)$} & \multicolumn{3}{c}{$\mathrm{H}_{2}$ selectivity } \\
\hline particles & $\begin{array}{c}f c c-\mathrm{Ru} \\
\text { particles }\end{array}$ & $\begin{array}{c}f c c-\mathrm{Ru} \\
\text { frames }\end{array}$ & $\begin{array}{c}h c p-\mathrm{Ru} \\
\text { particles }\end{array}$ & $\begin{array}{c}f c c-\mathrm{Ru} \\
\text { particles }\end{array}$ & $\begin{array}{c}f c c-\mathrm{Ru} \\
\text { frames }\end{array}$ \\
\hline $1 \mathrm{st}$ & 0.51 & 0.70 & 1.50 & $7.81 \%$ & $13.68 \%$ & $43.92 \%$ \\
\hline 5 th & 0.46 & 0.59 & 1.31 & $4.75 \%$ & $9.62 \%$ & $36.62 \%$ \\
\hline 10 th & 0.43 & 0.51 & 1.05 & $3.62 \%$ & $6.62 \%$ & $26.88 \%$ \\
\hline
\end{tabular}

